\title{
11 \\ Scaling the benefits of agri-environment schemes for biodiversity
}

Geoffrey Kay

\section{Key lessons}

- Agri-environment schemes have mixed outcomes for biodiversity, and more monitoring is needed particularly for certain taxonomic groups.

- Agri-environment scheme effectiveness is heavily reliant on the spatial scale of implementation, and addressing this at local and landscape scales is critical for advancing their application for conservation of biodiversity in agricultural landscapes.

- At local scales, information about how species respond to environmental features, as well as the impact of management actions, could improve site selection and effectiveness of management prescriptions.

- At landscape scales, the offsite benefits of agri-environment schemes could be enhanced by better understanding the impact of surrounding landscape context.

- Incorporating information about the patterns of diversity over large areas, as well as the role and sensitivity of habitat metrics to biodiversity, could greatly enhance the biodiversity benefits of agri-environment schemes. 
Demand for agri-environment schemes to counteract global biodiversity loss has resulted in the development of some large, continental-scale agri-environment schemes. While some schemes have been successful in addressing the social and policy elements of farmland conservation (Zammit 2013), very few have been able to demonstrate effective biodiversity outcomes across the scale of program implementation (Whittingham et al. 2007). One of the key reasons for this is that, in order to work across large spatial scales, programs have tended to employ rigid management actions, or a one-size-fits-all approach (Batáry et al. 2011; Kleijn and Sutherland 2003). However, recent studies have demonstrated that the effectiveness of agri-environment schemes is influenced by a number of scale-dependant factors, including the amount invested in agri-environment schemes (Dallimer et al. 2010; Hiron et al. 2013), surrounding landscape context (Batáry et al. 2011; Concepción et al. 2012; Gabriel et al. 2010), and the underlying delivery mechanisms used in scheme design (Hajkowicz et al. 2009; Siriwardena 2010). Designing better agri-environment schemes requires a greater understanding and incorporation of these scale-effects.

One of the critical aspects of scale relates to management rules applied to achieve agri-environment scheme goals (see Figure 11.1). Management rules can be applied at one of two scales: locally at the site (i.e. within a single management unit), or across the whole landscape (i.e. at multiple management units). Irrespective of the goal of a particular agri-environment scheme, both the local and landscapewide management rules are important for achieving conservation outcomes (Gonthier et al. 2014). If we want to conserve targeted species then it is important to not only protect key habitats but also the potential processes aiding their dispersal and other important aspects of their biology (see metapopulation theory). Conversely, if we want to conserve whole communities, we need to understand how they respond to local-scale management. Despite this recognition, our knowledge and integration of these scale-effects into agri-environment schemes remains very limited (Siriwardena 2010). For example, sitelevel management actions (such as prescribed or rotational grazing) remain poorly resolved (Briske et al. 2011), and landscape-scale dispersal information is poorly understood for many taxa (Driscoll et al. 2014). Better knowledge of local- and landscape-scale factors that influence conservation outcomes would therefore address a key knowledge gap and provide an opportunity to enhance biodiversity outcomes of agri-environment schemes. 
In this chapter, we address this knowledge gap by revealing opportunities to integrate scale-effects to improve agri-environment scheme effectiveness for biodiversity across both local and landscape scales. First, we address the need for biological monitoring over ecologically relevant time frames for quantifying scale-effects on agri-environment schemes. Summarising current knowledge of how local- and landscape-scale factors influence agri-environment schemes, we then provide novel research priorities at these scales.

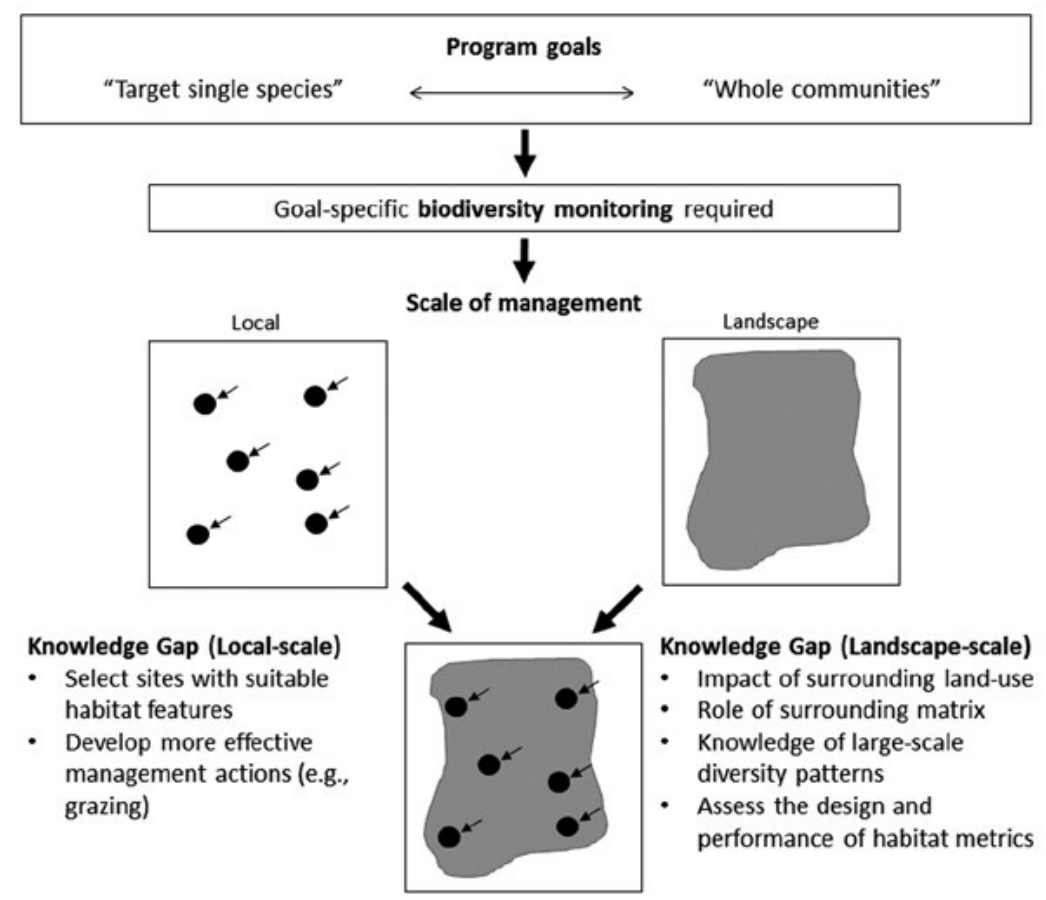

Figure 11.1: Conceptual flow for the advancement of agri-environment schemes through incorporation of scale-effects. Regardless of agri-environment scheme program goals, biodiversity monitoring is required to validate program success. Opportunities to enhance performance of agri-environment schemes by addressing key knowledge gaps at both local- and landscape-scale are identified.

Source: Author's research. 


\section{Monitoring outcomes of agri-environment schemes}

Quantifying scale-effects on agri-environment schemes relies on a thorough understanding of the biodiversity response to management decisions at different scales. However, despite the significant investment and widespread implementation, many agri-environment schemes have not demonstrated effective outcomes for biodiversity (Kleijn and Sutherland 2003; Lindenmayer et al. 2012; Michael et al. 2014). Amongst other reasons, this is due to a paucity of rigorous assessment and monitoring (Herzog 2005; Perkins et al. 2013), especially for certain taxonomic groups, such as reptiles (Michael et al. 2014). Even where monitoring data is available, our understanding of the scale-effects on biodiversity have largely emerged from what we know of agri-environment schemes in a limited set of regions (e.g. American and European landscapes) (Batáry et al. 2015). To properly assess the biodiversity responses to agri-environment schemes we need to develop robust, statistically verified scientific monitoring programs (Lindenmayer et al. 2012) across a wider set of ecological systems (see Chapter 3). Such programs must be designed around specific agri-environment scheme goals (i.e. single species versus whole communities), and focus on observing population- or community-level changes across multiple taxa at target sites, as well as comparable reference sites.

It is important to consider the time frames necessary for biodiversity response to agri-environment schemes when developing monitoring programs. The inability of many existing monitoring programs to show effective biodiversity response may not reflect failure of the program per se, but that insufficient time has passed for relevant ecological processes to succeed. This emphasises the need to continue monitoring over long time frames far exceeding policy cycles. Critically, however, this does not mean we need to wait until we detect positive change to identify the perfect program. Instead, the limited capacity demonstrated in agri-environment schemes for achieving mid-term outcomes could be addressed by identifying opportunities to enhance the current models. 


\section{Advancing agri-environment schemes through understanding scale-effects}

\section{Local scale}

Fundamentally, the success of any agri-environment scheme relies on the positive response of biodiversity to investment at the local (i.e. field or farm) scale. This is the smallest management scale within an agrienvironment scheme, typically 1-10 kilometres, to which landholders apply the funded conservation management actions.

These actions are generally targeted towards specific groups of organisms or agricultural practices, which often include (but are not limited to) promotion of native vegetation, soil health and habitat components (possibly for target species), and prevention of damaging management practices, such as fertilisation and overgrazing (Zammit et al. 2010). Positive biodiversity response in agri-environment schemes depends on two fundamental assumptions: suitable habitat is incorporated within the investment sites selected; and the imposed management actions enhance or maintain suitable conditions (e.g. habitat) for biota. Despite the wide application of agri-environment schemes, major knowledge gaps surround both of these assumptions (see Figure 11.1).

The incorporation of suitable habitat (or the provisioning for future habitat) is critical for achieving biodiversity gain in any agri-environment schemes program. This requires careful consideration of the sites being selected. However, one of the major assumptions regarding site selection is that all habitat within a given ecosystem or species range are equal in condition and extent. For example, native vegetation cover is considered important for a wide number of species (McElhinny et al. 2006) and so is included in the site selection of many Australian agri-environment schemes. However, in many ecosystems targeted under agri-environment schemes, little is known about which habitat features are most important for species. Moreover, the positive influence of specific environmental features is likely to vary for different species, whole communities, and across different biogeographic or climatic zones (Whittingham et al. 2007). It may be important to ask whether targeting certain habitat features, such as those that are important for rare species, can improve the 
effectiveness of agri-environment schemes for other biota. Indeed, some of the most important drivers of biodiversity may be climatic or landscape features (e.g. elevation), which cannot be influenced by management.

Central to agri-environment schemes policy is the use of carefully prescribed site-level management actions, which counteract the negative influence of agriculture on biodiversity. Management actions addressing the impact on biodiversity from wide-spread agricultural practices (e.g. livestock overgrazing, fertiliser application) are considered most desirable (Dallimer et al. 2010). Despite a focus on these management actions in agri-environment schemes, their role in averting biodiversity loss is poorly known. For example, there is little consensus on the impacts of livestock grazing as a management tool for biodiversity, despite widespread application and decades of research (Briske et al. 2011). A better understanding of the outcomes of management actions on biodiversity (particularly large-scale ones, such as livestock grazing) would have large implications for enhancing site-level response to agri-environment schemes.

\section{Landscape scale}

An underlying basis for successful agri-environment schemes is that they propagate positive biodiversity benefit from investment sites into the broader landscape. The extent to which this occurs depends heavily on the hostility of the surrounding landscape (Tscharntke et al. 2005). Yet the mechanisms remain poorly understood. This is particularly the case for species with limited dispersal (e.g. terrestrial invertebrates, reptiles), which are most sensitive to the negative impacts of fragmentation in an agricultural matrix.

Recent studies have found that the biodiversity response to agri-environment scheme investment is influenced by the context of the surrounding landscape (Carvell et al. 2011; Concepción et al. 2012), although this response is inconsistent and poorly resolved (Batáry et al. 2011). The greatest positive biodiversity response has been observed in landscapes with an intermediate level of 'complexity' - the degree of variation within landscape (Concepción et al. 2012). Despite this, other studies have found inconsistent results for different taxonomic groups for both simple and complex landscapes, and that the effect of complexity depends on the type of surrounding vegetation (Batáry et al. 2011). Landscapes with a greater 
proportion of area covered by management demonstrate stronger positive biodiversity response (Baker et al. 2012; Dallimer et al. 2010), although whether this is in response to direct agri-environment scheme investment or greater inclusion of suitable landscapes remains unclear. A greater number of studies exploring the influence of surrounding landscape on agri-environment schemes success are clearly required to systematically investigate each of these conflicting elements. Given that our current understanding is nearly exclusively from European (e.g. Concepción et al. 2012) and American landscapes (e.g. Carvell et al. 2011), future investigations of this kind within Australian landscapes are critical for providing a more rounded understanding of how to enhance agri-environment schemes at landscape scales.

In addition to understanding how landscape context can affect agri-environment schemes success, it is important to know why landscape context may affect agri-environment schemes success. One of the key assumptions in agri-environment schemes policy is that investment will promote even propagation of biodiversity into the broader landscape (Whittingham et al. 2007), although it is clear that dispersal into surrounding landscapes for some species (e.g. grounddependant species such as reptiles) will be more challenging than others. This is because the type of land-use and style of management employed in surrounding landscapes is likely to greatly influence the capacity of species to disperse, particularly for those with limited dispersal ability most at risk to fragmentation. For agri-environment schemes to better support the conservation of such species in the broader landscape, it is crucial that we gain a greater understanding of how these species disperse in different matrix environments. Nonhostile matrix environments can then be created. We can achieve this by examining the effect of surrounding land-use (e.g. cropped landscapes), as well as the impact of certain management actions (e.g. grazed and open pastures versus ungrazed and dense pastures), on the movement of limited-dispersing species.

The capacity for agri-environment schemes to achieve landscape-scale, positive biodiversity response is dependent largely on the ability of these schemes to adequately capture the best elements of the landscape. Agri-environment schemes that pay landholders for biodiversity actions create a market for biodiversity, but the value assigned to actions is determined by metrics adopted in the scheme (Zammit et al. 2010). Despite widespread use of habitat metrics in biodiversity 
markets, relatively little attention has been paid to their design and performance (Hajkowicz et al. 2009), and their capacity to summarise the actual biodiversity present at a site within an agri-environment scheme (Oliver et al. 2014). The use of metrics that misrepresent the condition of the target ecological community has dire implications for the overall success of an agri-environment scheme, and yet we have very little knowledge linking biodiversity response to metric scores for agri-environment schemes worldwide.

Finally, landscape-wide biodiversity outcomes for agri-environment schemes can also be achieved by developing a broader understanding of the patterns of diversity across the landscape. Currently, the distribution of diversity is known at a very general level - for example, species richness is greater near the equator (Gaston 2000) - with little or no understanding of diversity patterns at landscape scales for most groups of organisms. Understanding landscape patterns of diversity would have considerable benefit for agri-environment schemes by allowing managers to develop regionally targeted conservation strategies. For example, focused management of lowquality sites within high diversity areas (hotspots) could be used to achieve high conservation gain. Although the tools for developing such diversity maps have now been developed (Ferrier et al. 2007), they have yet to be integrated into agri-environment schemes, despite the clear conservation benefits of doing so.

\section{Conclusions}

Enhancing the effectiveness of agri-environment schemes for biodiversity conservation requires management attention at multiple scales, from local to landscape. We have identified key knowledge gaps and priority areas for research that would improve the rigid one-size-fits-all model commonly applied to agri-environment schemes. We contend that the effectiveness of agri-environment schemes must be advanced if we are to counter the effects of agriculture on biodiversity, and that monitoring data across multiple scales, for a much wider range of taxa, is required. 


\section{References}

Baker, D.J., S.N. Freeman, P.V. Grice, et al. (2012) 'Landscape-scale responses of birds to agri-environment management: A test of the English Environmental Stewardship scheme', Ecological Applications 49: 871-82. DOI:10.1111/j.1365-2664.2012.02161.x.

Batáry, P., A. Báldi, D. Kleijn and T. Tscharntke (2011) 'Landscapemoderated biodiversity effects of agri-environmental management: A meta-analysis', Proceedings of the Royal Society B: Biological Sciences 278: 1894-902. DOI:10.1098/rspb.2010.1923.

Batáry, P., L.V. Dicks, D. Kleijn and W.J. Sutherland (2015) 'The role of agri-environment schemes in conservation and environmental management', Conservation Biology 29(4): 1006-16. DOI:10.1111/ cobi. 12536 .

Briske, D.D., N.F. Sayre, L. Huntsinger, et al. (2011) 'Origin, persistence, and resolution of the rotational grazing debate: Integrating human dimensions into rangeland research', Rangeland Ecology and Management 64: 325-34. DOI:10.2111/REM-D-10-00084.1.

Carvell, C., J.L. Osborne, A.F.G. Bourke, et al. (2011) 'Bumble bee species' responses to a targeted conservation measure depend on landscape context and habitat quality', Ecological Applications 21: 1760-71. DOI:10.1890/10-0677.1.

Concepción, E.D., M. Díaz, D. Kleijn, D., et al. (2012) 'Interactive effects of landscape context constrain the effectiveness of local agri-environmental management' , Ecological Applications 49:, 695705. DOI:10.1111/j.1365-2664.2012.02131.x.

Dallimer, M., K.J. Gaston, A.M.J. Skinner, et al. (2010) 'Field-level bird abundances are enhanced by landscape-scale agri-environment scheme uptake', Biology Letters 6: 643-6. DOI:10.1098/rsbl. 2010.0228 .

Driscoll, D.A., S.C. Banks, P.S. Barton, et al. (2014) 'The trajectory of dispersal research in conservation biology: Systematic review', PLOS ONE 9: e95053. DOI:10.1371/journal.pone.0095053. 
Ferrier, S., G. Manion, J. Elith and K. Richardson (2007) 'Using generalized dissimilarity modelling to analyse and predict patterns of beta diversity in regional biodiversity assessment', Diversity and Distributions 13: 252-64. DOI:10.1111/j.1472-4642.2007.00341.x.

Gabriel, D., S.M. Sait, J.A. Hodgson, et al. (2010) 'Scale matters: the impact of organic farming on biodiversity at different spatial scales', Ecology Letters 13: 858-69. DOI:10.1111/j.1461-0248.2010.01481.x.

Gaston, K.J. (2000) 'Global patterns in biodiversity', Nature 405: 22027. DOI:10.1038/35012228.

Gonthier, D.J., K.K. Ennis, S. Farinas, et al. (2014) 'Biodiversity conservation in agriculture requires a multi-scale approach', Proceedings of the Royal Society B: Biological Sciences 281: 20141358. DOI:10.1098/rspb.2014.1358.

Hajkowicz, S., K. Collins and A. Cattaneo (2009) 'Review of agrienvironment indexes and stewardship payments', Environmental Management 43: 221-36. DOI:10.1007/s00267-008-9170-y.

Herzog, F. (2005) 'Agri-environment schemes as landscape experiments', Agriculture, Ecosystems and Environment 108: 175-177. DOI:10.1016/j.agee.2005.02.001.

Hiron, M., Å. Berg, S. Eggers, et al. (2013) 'Bird diversity relates to agri-environment schemes at local and landscape level in intensive farmland', Agriculture, Ecosystems and Environment 176: 9-16. DOI:10.1016/j.agee.2013.05.013.

Kleijn, D. and W.W. Sutherland (2003) 'How effective are European agrienvironment schemes in conserving and promoting biodiversity?', Journal of Applied Ecology 40, 947-69.

Lindenmayer, D.B., C. Zammit, S.J. Attwood, et al. (2012) 'A novel and cost-effective monitoring approach for outcomes in an Australian biodiversity conservation incentive program', PLOS ONE 7: 1-11. DOI:10.1371/journal.pone.0050872.

McElhinny, C., P. Gibbons, C. Brack and J. Bauhus (2006) 'Faunahabitat relationships: A basis for identifying key stand structural attributes in temperate Australian eucalypt forests and woodlands', Pacific Conservation Biology 12: 89-110. 
Michael, D.R., J.T. Wood, M. Crane, R. Montague-Drake and D.B. Lindenmayer (2014) 'How effective are agri-environment schemes for protecting and improving herpetofaunal diversity in Australian endangered woodland ecosystems?' Journal of Applied Ecology 51: 494-504. DOI:10.1111/1365-2664.12215.

Oliver, I., D.J. Eldridge, C. Nadolny and W.K. Martin (2014) 'What do site condition multi-metrics tell us about species biodiversity?' Ecological Indicators 38: 262-71. DOI:10.1016/j. ecolind.2013.11.018.

Perkins, A., H. Maggs, A. Watson and J. Wilson (2010) 'Adaptive management and targeting of agri-environment schemes does benefit biodiversity: A case study of the corn bunting Emberiza calandra', Journal of Applied Ecology 48: 514-22.

Perkins, G., A. Kutt, E.P. Vanderduys, J. Perry and J.J. Perryl (2013) 'Evaluating the costs and sampling adequacy of a vertebrate monitoring program', Australian Journal of Zoology 36: 373-80.

Siriwardena, G.M. (2010) 'The importance of spatial and temporal scale for agri-environment scheme delivery', Ibis 152(3): 515-29. DOI:10.1111/j.1474-919X.2010.01034.x.

Tscharntke, T., A.M. Klein, A. Kruess, I. Steffan-Dewenter and C. Thies (2005) 'Landscape perspectives on agricultural intensification and biodiversity: Ecosystem service management', Ecology Letters 8, 857-74. DOI:10.1111/j.1461-0248.2005.00782.x.

Whittingham, M.J., J.R. Krebs, R.D. Swetnam, et al. (2007) 'Should conservation strategies consider spatial generality?: Farmland birds show regional not national patterns of habitat association', Ecology Letters 10: 25-35. DOI:10.1111/j.1461-0248.2006.00992.x.

Zammit, C., S. Attwood and E. Burns (2010) 'Using markets for woodland conservation: Lessons from the policy-research interface', Temperate Woodland Conservation and Management (eds D.B. Lindenmayer, A.F. Bennett and R.J. Hobbs), CSIRO Publishing, Melbourne, pp. 297-307.

Zammit, C.C. (2013) 'Landowners and conservation markets: Social benefits from two Australian government programs', Land Use Policy 31: 11-16. DOI:10.1016/j.landusepol.2012.01.011. 
This text is taken from Learning from agri-environment schemes in Australia: Investing in biodiversity and other ecosystem services on farms, edited by Dean Ansell, Fiona Gibson and David Salt, published 2016 by ANU Press, The Australian National University, Canberra, Australia. 